\title{
JUEGOS CIENTÍFICOS Y DE CONSTRUCCIÓN EN LA EDUCACIÓN Y EN LA INDUSTRIA: VALORES E INTERACCIONES EN ESPAÑA
} $(1920-1936)^{\alpha}$

\author{
Scientific and construction toys in education and industry: \\ values and interactions in Spain (1920-1936)
}

\section{Víctor Guijarro Mora ${ }^{\mathrm{B}}$}

Fecha de recepción: 03/05/2020 • Fecha de aceptación: 18/09/2020

Resumen. El presente estudio contempla la extensión e influencias mutuas de un tipo de prácticas renovadoras promovidas en dos dimensiones de la educación, la formal y la no formal, en el segundo y tercer decenios del siglo veinte en España. Estas coincidieron, como parte de la crítica a la escuela tradicional, en un replanteamiento de las relaciones de los estudiantes y aficionados con los materiales empleados en el proceso de aprendizaje. En ellas se defendía que el objeto en lugar de ser una realidad lejana, simbólica e intocable, sujeto a la concepción memorista y verbalista de la educación, debía ser un útil próximo y manipulable que contribuyera a despertar las aptitudes inventivas del alumnado, especialmente en las disciplinas científicas. Así, se analizarán las conexiones y diferencias entre los principios de los movimientos incluidos en la enseñanza activa y las estrategias de las empresas dedicadas a la fabricación de juguetes de construcción, en particular las llevadas a cabo por una marca, Meccano, altamente representativa en la época en el sector aludido.

Palabras clave: Enseñanza activa; Fabricantes de juguetes instructivos; Objetos educativos; Trabajos manuales; Meccano; 1920-1936; España.

\footnotetext{
a El estudio se ha llevado a cabo en el marco del proyecto de investigación 'Desafíos educativos y científicos de la Segunda República: internacionalización, popularización e innovación en universidades e institutos' (Convocatoria 2018 de Proyectos de I+D de Generación de Conocimiento, PGC2018-097391B-I00). El autor desea expresar su agradecimiento a las personas que en el proceso de evaluación y revisión han realizado contribuciones a mejorar las ideas y planteamientos expuestos en el manuscrito.

B Departamento de Ciencias de la Educación, Lenguaje, Cultura y Artes, Facultad de Ciencias Jurídicas y Sociales, Universidad Rey Juan Carlos, en c/Tulipán, s/n, Móstoles, 28933, Madrid, España. victor.guijarro@urjc.es (D) https://orcid.org/0000-0002-8570-5119
}

Cómo citar este artículo: Guijarro Mora, Víctor. «Juegos científicos y de construcción en la educación y en la industria: valores e interacciones en España (1920-1936)». Historia y Memoria de la Educación 14 (2021): 511-546 
Abstract. This study contemplates the extension and mutual influences of certain kinds of renovating practices promoted in two realms of education, formal and non-formal, in the second and third decades of the 20th century in Spain. As part of a broader critique of the traditional school, these new perspectives coincided in their rethinking of the students' and amateurs') relationship with the materials used in learning process. For them, the object, rather than constituting a distant, symbolic and untouchable reality-subject to a memory-based, verbalist conception of education-, should be a close, touchable tool whose handling contributes to awakening the inventive abilities of students, especially in scientific disciplines. We will analyze the connections and differences between the principles of movements included in active teaching and the strategies of companies dedicated to the manufacture of construction toys, particularly those carried out by a preeminent brand working in this sector at the time, Meccano.

Keywords: Active education; Instructive toy makers; Teaching objects; Manual work; Meccano; 1920-1936; Spain.

\section{INTRODUCCIÓN}

En los tres primeros decenios del siglo veinte se consolida en diversos círculos académicos la idea de que el cambio en los procedimientos de aprendizaje pasaba por dedicar una atención especial a una cultura educativa que favoreciera la acción y el dinamismo en el espacio del aula. Un presupuesto que demandaba una atención preferente a la interacción del estudiante con el mundo material, representado en la forma de piezas intercambiables, de artificios desmontables, de figuras geométricas y de objetos cotidianos simples. Como consecuencia, se estimulaban las capacidades sensoriales y corporales y se favorecía la oposición al intelectualismo de la escuela tradicional basada en el memorismo y el verbalismo.

Además, en la instrucción no formal, los fabricantes de juguetes instructivos ofertaban modos de entretenimiento que permitían, mediante la manipulación de piezas estandarizadas, aprender la lógica que dominaba las destrezas científicas básicas, según se aseguraba en sus promociones publicitarias. Este era el propósito de las cajas de construcciones y de otros equipos que destinaban algunas marcas al mercado doméstico, ${ }^{1}$ presupuestos que mantenían analogías con la pretensión de los reformadores de la educación.

\footnotetext{
1 Melanie Keene, «Every boy and girl a scientist. Instruments for children in Interwar Britain», ISIS 98, no. 2 (2007): 275. En el trabajo nos vamos a referir básicamente a los conjuntos de construcción
} 
Por un lado, las grandes compañías del juguete, cuando intervienen en el mercado educativo, lo hacen reproduciendo el discurso ya presente en la escuela activa, ${ }^{2}$ la que favorecía la participación de los alumnos en el proceso de aprendizaje. Ahora bien, dentro de la retórica empresarial adquiere un valor diferente. Esta segunda vida de los tópicos, iconos y estereotipos estaba destinada a crear nuevos imaginarios y en parte también a cuestionar la escuela tradicional.

Por el otro, la industria, a través de redes de distribuidores influye igualmente en las prácticas de la escuela oficial, facilitando la introducción de sus modelos en el currículo público.

Los dos efectos mencionados constituyen los temas de análisis propuestos en este trabajo, cuyo fin es comprobar los procedimientos empleados en las estrategias publicitarias persuasivas de los empresarios y los matices que adquirieron algunas de las imágenes que compartieron con la retórica de la educación activa, como las de simplicidad, juego, ${ }^{3}$ creatividad y construcción. Para ello se seleccionará un corpus documental perteneciente a una de las industrias más representativas del período examinado, la inglesa Meccano, que alcanzó una notable difusión en España en los años 1920 y 1930.

Se examinarán así las influencias mutuas entre estas dos dimensiones de la educación, la formal y la no formal, ${ }^{4}$ en un momento de replanteamiento

dedicados a la ingeniería y los montajes científicos; para otros modelos y otros propósitos, especialmente relacionados con la arquitectura, véase Juan Bordes, Historia de los juguetes de construcción (Madrid: Cátedra, 2012).

2 En este concepto de contornos indefinidos agrupamos diversos movimientos y colectivos que promovieron reformas en los estudios de la naturaleza («Nature Studies» en los países anglosajones), cuyo propósito era despertar la curiosidad y el espíritu crítico de los alumnos, y que mantiene lazos con la escuela nueva y la escuela progresiva; véase Peter Gordon y Denis Lawton, Dictionary of British Education (Londres: Woburn Press, 2005, $1^{\text {a }}$ ed. de 2003)

3 Sobre la importancia del juego como recurso educativo en el marco institucionista y renovador español, en el que se promueve la enseñanza activa, véanse los trabajos de Andrés Payá Rico, «Aprender deleitando. El juego infantil en la pedagogía española del siglo XX». Bordón. Revista de Pedagogía 65, no. 1 (2013): 37-46; «El juego popular y tradicional en la historia de la educación española contemporánea», Historia de la Educación 38 (2019): 43-49, y «El juego y el juguete en la historia de la escuela», en Óscar Barberá, Alejandro Mayordomo Pérez, coords. Escoles i mestres: dos siglos de historia y memoria en Valencia (Valencia: Universidad de Valencia, 2017), 137-152.

4 Partimos de la distinción entre educación formal, no formal e informal realizada por Jaume Trilla Bernet en La educación fuera de la escuela. Ámbitos no formales y educación social (Barcelona: Ariel, 1993), 13. En general, la primera pertenece a las estructuras del currículo educativo oficial y la 
de los patrones de la escuela tradicional, así como los agentes que facilitaron esas mediaciones.

\section{ENSEÑANZA ACTIVA, «MANUALISMO»Y LENGUAJE CORPORAL}

En distintos lugares se consolidaron focos de irradiación de nuevos planteamientos en la manera de enseñar los contenidos del currículo escolar. Todos ellos se presentaron como alternativas a una suerte de escuela «tradicional» o clásica. Algunos alcanzaron renombre internacional y han sido objeto de diversos estudios y atención, como la Escuela Decroly (en Bélgica), la de Bedales (Inglaterra), Seidel (Alemania), la Casa dei Bambini (perteneciente a la institución Montessori, Italia), la Institución Libre de Enseñanza (España), por señalar solo algunos ejemplos. El rasgo común de estas experiencias es que la atención de sus programas estaba centrada preferentemente en los niveles primarios de la educación (hasta aproximadamente 12 años). Pero también encontramos en algunas propuestas planes de mayor alcance que se extendían a la enseñanza secundaria y a la formación en general.

Estos proyectos coincidían en la atención preferente que dedicaban a los ejercicios prácticos que tenían lugar en las aulas, un concepto que abarcaba los trabajos manuales, la construcción de dispositivos simples o más complejos y las experiencias que llevaban a cabo los estudiantes con diferentes tipos de materiales en las asignaturas de física y química.

Comprobamos esta predisposición en los pensionados españoles, influidos por la mentalidad institucionista, que viajaron a centros belgas, franceses e ingleses principalmente. En las crónicas de sus visitas destacan las dimensiones prácticas de las enseñanzas, como hace el maestro Dionisio Prieto Fernández, en cuya memoria titulada «El trabajo manual en las escuelas primarias de París y Bruselas», relativa a las escuelas normales parisinas, se lee que sus propósitos eran:

1. ${ }^{\circ}$ Romper la monotonía de los ejercicios puramente intelectuales, en los cuales el niño raramente tiene ocasión de ejercitar sus sentidos. $2 .^{\circ}$ Desenvolver en cierta medida la destreza de la

segunda, no, pudiéndose llevar a cabo, si bien no exclusivamente, en contextos domésticos mediante juegos y entretenimientos. 
mano, pero sobre todo la exactitud de1 ojo por la observación continua de formas geométricas regulares y por la apreciación de las relaciones entre sus dimensiones. ${ }^{5}$

Similares atenciones y juicios encontramos en las memorias de los inspectores de primera enseñanza Ángel Rodríguez Mata ${ }^{6}$ y Antonio Ballesteros Usano, ${ }^{7}$ donde se hace notar el contraste entre los modelos francés y belga, y donde se afirma, aludiendo al último (más descentralizado y menos intelectualista), que «Todo se funda en el hacer, adiestrándoles la vista, las manos y el gusto».

En el período de la Segunda República, el ideario de la escuela nueva, con el fomento de la «habilidad y el dominio manual», aparece en los lugares preferentes de la política educativa, al menos sobre el papel. ${ }^{8}$ Una de las figuras reconocibles en el impulso de ese movimiento en el período mencionado fue Lorenzo Luzuriaga. ${ }^{9}$ En la enseñanza secundaria, el lugar donde mayor visibilidad lograron las propuestas mencionadas fue en los proyectos de los Institutos-Escuela auspiciados por la Junta para la Ampliación de Estudios. El contacto activo de los estudiantes con los materiales, como se verá, es uno de los ejes sobre los que pivotan las enseñanzas.

En los Institutos-Escuela establecidos -el primero- en 1918, se asumieron de igual manera los planteamientos del «manualismo». Los trabajos prácticos se contemplaban como manipulaciones de laboratorio al servicio de las ciencias. Estas tareas, se decía, además de servir «para la educación de los sentidos, para alcanzar la perfecta correlación entre

\footnotetext{
5 Junta para la Ampliación de Estudios, Anales XVIII (1924): 94.

6 Ángel Rodríguez Mata, «El método activo aplicado en las escuelas de Francia y Bélgica», JAE, Anales XIX (1924).

7 Antonio Ballesteros Usano, «Características de la enseñanza primaria en Francia, Bélgica y cantón suizo de Neuchatel», JAE, Anales XVIII (1924); véanse por ejemplo las pp. 230-231. En la p. 218 se afirma que la enseñanza es democrática, en la medida en que se interesa por desarrollar la individualidad de los niños dentro del orden de la clase.

8 Adolphe Ferrière, «École», en Sébastien Faure, Encyclopédie anarchiste (París: La Librairie internationale, 1925-1934, tome 2), 622-623. Sobre su influencia en la Segunda República, Teresa Marín Eced, «Influencias europeas en la formación profesional de docentes españoles durante la II República Española», Revista de Educación 285 (1988): 93-110.

9 Pilar Maestro, «Lorenzo Luzuriaga y la educación republicana», Pasajes: Revista de pensamiento contemporáneo 21-22 (2007): 19-42.
} 
la mente y la mano, y como auxiliares para el desarrollo mental», representaban una «excelente ocasión para estudios con los cuales pueden combinarse, v. gr.: las Matemáticas, la Física, las Ciencias naturales» ${ }^{10} \mathrm{El}$ taller de carpintería, por ejemplo, estuvo dedicado en el curso 1926-27 a elaborar materiales para enseñanzas científicas. ${ }^{11}$ A continuación, revisamos algunas de las experiencias que se llevaron a cabo que, supuestamente, representaban una proyección de las propuestas asumidas.

La lectura cuidadosa de los textos compuestos por León y Catalán ${ }^{12}$ proporciona una valiosa información acerca del alcance y problemas de la enseñanza activa de la ciencia, dada la escasa documentación disponible sobre lo que ocurría dentro de las aulas. De acuerdo con estos manuales-informe, en los recintos educativos se observan diversas formas de manejar los materiales. En algunos ejercicios se reconoce fácilmente que pertenecen a un grupo de útiles que son accesibles a los alumnos y que estos son capaces de manipular. Los primeros que forman parte del plan curricular son sobre medidas de longitud, superficie y volumen. En cuanto a la longitud basta disponer unos alfileres en la línea curva y utilizar una cuerda; una vez señalados los límites se traslada la medida sobre un "decímetro». Posteriormente, "se debe hacer entablar una pequeña discusión, entre los que han empleado diferentes sistemas, sobre cuál de ellos da el valor más exacto». ${ }^{13}$ La coordinación en esta práctica, como otras en las que se emplean materiales simples y manejables, se efectúa entre la mano y el ojo, prestando atención a la exactitud al comparar diferentes longitudes. Pero igualmente se aprenden en este proceso elementos del conocimiento tácito, fundamentales en las operaciones manuales y corporales en general, pero que no son

\footnotetext{
10 JAE, Memoria correspondiente a los cursos 1922-3 y 1923-4, 325; en Víctor Guijarro y Leonor González, «La presencia de la tecnología en la utopía pedagógica: el Instituto de San Isidro y los Institutos-Escuela promovidos por la JAE», en Leonor González y Vicente J. Fernández, El Instituto de San Isidro. Saber y patrimonio. Apuntes para una historia (Madrid: CSIC, 2013), 182.

11 «En el taller de carpintería para los niños se estableció, durante el curso, una relación entre esta clase de trabajo manual y la clase de Física, construyendo los alumnos diversos aparatos y utensilios destinados a las prácticas de esta asignatura. Existe el propósito de continuar por este camino en los próximos cursos, construyendo varios aparatos ya proyectados y enlazando la enseñanza manual con la Física y probablemente con otras ramas de la enseñanza.» (JAE, Memoria, 1929, 317)
}

12 Exposición de la enseñanza cíclica de la Física y la Química, curso 1931 (Madrid: JAE, 1931); 1934 (Madrid: JAE, 1934); curso 1935 (Madrid: JAE, 1935).

13 Andrés León Maroto y Miguel Ángel Catalán, Exposición de la enseñanza cíclica de la Física y la Química (Madrid: JAE, 1931), 15. 
reconocidos en los análisis y explicaciones de este tipo de trabajos experimentales. Hay indicaciones que recuerdan de manera indirecta a otro tipo de competencias que se adquieren inconscientemente, como cuando se advierte que «Es conveniente hacer una segunda lectura», poniendo, por ejemplo, un número doble de alfileres. Son comentarios o consejos (habitualmente precedidos por el término «conviene») que no corresponden tanto a la estructura fundamental y explícita de la comprobación propuesta como a la implícita, y que son asimilados después de una extensa experiencia de ensayos y errores. ${ }^{14}$

Hay otros ejercicios en los que los resultados del uso de los materiales y su disposición, aunque sean accesibles (alfileres, espejos...) es altamente previsible, dado que están al servicio de la visualización de leyes elementales. Es tal la confianza en la replicación de los modelos que las pequeñas desviaciones son atribuidas a la complejidad del fenómeno estudiado o a otras circunstancias accidentales. Esto es lo que ocurre con los ejercicios relativos a la propagación, reflexión y refracción de la luz, donde hay poco margen para el descubrimiento y la experiencia consiste en comprobar la coincidencia entre el valor estimado y el que se encuentra en unas tablas. Pero cualquier discrepancia más allá de las cantidades admisibles es considerada simplemente un error. Se trata solo, como se reconoce, de «hacer ver», no de construir.

Puede distinguirse otra categoría de experiencias de contacto manual en la que se emplean objetos prefabricados, clásicos en las colecciones de los gabinetes, aunque, en principio, su uso según el plan pedagógico asumido no fuera recomendable. Son, entre otros, el prisma y la báscula, que no corresponden precisamente a la categoría de material simple. De nuevo, con el primero, el ejercicio está centrado en comprobar las diferencias entre las estimaciones y los valores teóricos, en este caso aplicado a la desviación de un rayo. Con el segundo, una parte de la experiencia consiste en conocer el propio instrumento. Aquí se añaden algunas precauciones que corresponden a la adquisición de las destrezas de uso de un aparato y que forman parte igualmente de los elementos del conocimiento tácito,

\footnotetext{
14 De este orden es la advertencia de la experiencia contemplada para «establecer» la ley de la palanca, donde se afirma que en el montaje del aparato se emplea «Un doble decímetro, una cuña de madera con la arista no muy pronunciada, más bien un poco matada, con lo cual se facilitará el mantener luego el equilibrio, y dos corchos para evitar sea muy grande la oscilación del doble decímetro» (León y Catalán, Exposición, 38).
} 
como «Ver si los platillos están limpios y secos. Ver si el fiel coincide con el cero cuando los platillos no tienen peso. Colocar el cuerpo que se va a pesar en el platillo izquierdo y las pesas en el derecho [...] $» .^{15}$

Hay una última categoría de experiencias que no son intuitivas y que probablemente tampoco pertenezcan al grupo de las que llevan a cabo los alumnos. En este caso lo que se busca es promover la capacidad de observación-reacción ante una demostración, con preguntas que guían las respuestas hacia un resultado previsto, como si se siguiera el método socrático. Son las que tienen lugar empleando los materiales que ilustran los principios de Arquímedes y de Pascal. ${ }^{16}$ Con estas prácticas se pretendía más que estimular una competencia de coordinación motora y visual, entrenar la atención para aislar los elementos que son relevantes de un fenómeno complejo.

Además de estas evidencias conocemos otros escasos ejemplos, de los que contamos con pruebas indirectas, en los que se promovió la interacción del estudiante con el material como un recurso pedagógico y epistemológico, ya que los propósitos perseguidos eran facilitar la comprensión de los contenidos y la asimilación de rutinas relativas a los procedimientos científicos de investigación y comprensión del mundo.

El profesor José Estalella también realizó contribuciones al fomento y organización de este estilo de aproximación al material, en el que se repiten expresiones que recuerdan la importancia de poner en las manos de los estudiantes los objetos. Estalella estuvo comprometido desde sus inicios con el proyecto de los Institutos-Escuela, y fue nombrado en 1932 director de la sede que se abrió en Barcelona. Escribió varios trabajos en los que defendía la visión del aprendizaje de la física y la química como un juego participativo que había que proteger contra las tentaciones de la solemnidad. ${ }^{17}$

15 León y Catalán, Exposición, 42.

16 En relación con estas propiedades las cuestiones planteadas son «¿Por qué no baja el mercurio completamente? ¿Qué sucederá al nivel de mercurio en el interior del tubo si la presión atmosférica aumentase o disminuyese? ¿Qué queda sobre la superficie del mercurio en el interior del tubo?» (León y Catalán, Exposición, 60).

17 Dos textos representativos de esta orientación son las dos partes de «La simplificación del material escolar de Física y Química», publicadas ambas en la Revista de Segunda Enseñanza en los años 1925 y 1926 respectivamente. En estos trabajos se defendía que la tarea del enseñante debe ser guiar a los alumnos en el reconocimiento de la multitud de materiales más o menos simples que tiene a su 
Estos enfoques de la enseñanza científica, que contaron con antecedentes en el siglo diecinueve, se intentaron impulsar en la educación formal del primer tercio del siglo veinte con resultados desiguales, ya fuera por su excepcionalidad o por su discontinuidad. Atendiendo a los datos disponibles, no puede afirmarse por tanto que fuese una práctica generalizada; más bien fue un movimiento minoritario, aunque al menos sí fue conocida por múltiples maestros que asistían a los cursos impartidos en el Museo Pedagógico Nacional o a las escuelas normales, como la de Guadalajara, dirigida por Modesto Bargalló, profesor comprometido con la orientación pedagógica descrita.

\section{VALORES DEMOCRÁTICOS DEL «MANUALISMO»}

También podemos asegurar que, junto con su consideración como un ensayo pedagógico y epistemológico, como se ha mencionado, la promoción de esta forma de entender la formación científica se inscribía para sus defensores en una cosmovisión más amplia que contemplaba no solo transmitir competencias, sino formas de vida presentes en una educación integral. En esta manera de entender la educación hay que enmarcar las posiciones, entre otras, de Manuel Bartolomé Cossío y el pragmatismo de John Dewey.

Cossío, director del Museo Pedagógico Nacional desde 1882, mantenía que la educación técnica y particularmente el entrenamiento de los estudiantes con los materiales no tenía como cometido la formación de aprendices, sino el desarrollo integral del ser humano, un ideal que tenía un alcance preferentemente moral. ${ }^{18} \mathrm{Y}$ este propósito estaba vinculado

\footnotetext{
alrededor para verificar y descubrir sin intermediarios los principios naturales. En concreto, en el dedicado a la Física se podía leer lo siguiente: «Dejemos de recordar los aparatos clásicos de demostración; si los detesto, detesto igualmente, y a veces más, todos los esfuerzos hechos para imitarlos. No hablemos de ellos; no los tomemos nunca por norma o por modelo. Todos llevan el estigma del proceso mediante el cual se ha permitido construir un objeto de elevado precio para los profesores de traje de etiqueta que, encerrados en su torre de marfil, temían lastimarse los dedos por el contacto con la ruda realidad. Solo excepcionalmente pueden sacarse de aquellos aparatos enseñanzas. En general vale más proceder, razonar y avanzar como si no existiesen», José Estalella, «La simplificación del material escolar de Física y Química», Enseñanza media, 80-83 (1960): 639.

18 Palabras pronunciadas en 1906, recogidas por Eugenio Otero Urtaza, Manuel Bartolomé Cossío: pensamiento pedagógico y acción educativa (Madrid: Centro de Publicaciones del Ministerio de Educación y Ciencia, CIDE, 1994), 155-156; véase Víctor Guijarro, Artefactos y acción educativa. La cultura del objeto científico en la enseñanza secundaria en España (1845-1930) (Madrid: Dykinson, 2018), 48-49.
} 
con el modo de emplear los materiales disponibles en la clase. «Toda educación debe ser esencialmente creadora», afirmaba. De esta manera, no debían admitirse en las aulas objetos previamente manufacturados, porque la educación consistía precisamente en el proceso de elaboración de los propios artefactos que, como un termómetro, por mencionar un ejemplo, se usaban para estudiar las leyes naturales. ${ }^{19}$

A mi juicio, uno de los pensadores que realizó contribuciones significativas destinadas a transformar la praxis manual en un proyecto político fue John Dewey, autor con una destacada presencia en España. ${ }^{20}$ Revisaremos algunas de las ideas que aparecen en particular en dos obras representativas, Democracia y educación (1 ${ }^{\mathrm{a}}$ ed. de 1916), publicada por primera vez en español en los años 1926 y 1927 por Ediciones de La Lectura $^{21}$, y Experiencia y educación (1938). ${ }^{22}$

Además de las diversas consideraciones que aparecen en la obra, en el apartado específicamente dedicado a explicar en qué consiste la democratización de la educación sostiene que en el espacio del aula los individuos comparten sus intereses, de tal manera que la acción de uno de ellos debe contemplar la acción de los demás. Estas prácticas participativas presuponen desestimar «aquellas barreras de clase, raza y territorio nacional que impiden que el hombre perciba la plena significación de su actividad». ${ }^{23}$ De esta manera, ampliando el número de estímulos a los que una persona ha de responder se asimilan los hábitos que corresponden a un modo de vivir asociado, que supera los contornos de unos intereses parciales y limitados. Según estos principios, la educación no debe estar al margen del entorno social: «El material de los estudios

\footnotetext{
19 Ya antes, Francisco Giner de los Ríos, creador y director de la Institución Libre de Enseñanza, había contemplado esta correlación entre la educación manual y la formación integral: «La Institución Libre es también la primera que en España ha introducido el trabajo manual en toda la enseñanza primaria, y tal vez una de las primeras en Europa que lo ha incluido en la secundaria por considerarlo un elemento indispensable, no solo de la educación técnica, sino, dentro de ciertos límites, de toda la educación racional humana», Francisco Giner de los Ríos, Obras selectas, ed. de Isabel Pérez-Villanueva Tovar (Madrid: Austral, 2004), 318. Las palabras anteriores fueron pronunciadas en el Congreso Internacional sobre Educación, celebrado en Londres en 1884.

20 Véase Maestro, «Lorenzo Luzuriaga», 36-37.

21 Lorenzo Luzuriaga realizó una traducción para la editorial Losada publicada en 1967.

22 Traducida por Lorenzo Luzuriaga para la editorial Losada en 1939, ya en el exilio.

23 John Dewey, Democracia y educación. Una introducción a la filosofía de la educación (Madrid: Ediciones Morata, 1998), 82.
} 
escolares traduce en forma concreta y detallada los significados de la vida social corriente que es deseable transmitir». ${ }^{24}$

Dewey dice más adelante al exponer los procedimientos de enseñanza que deben cultivarse que el conocimiento más inmediato y que más profundamente se conserva es el de «cómo hacer». Es bajo esta premisa como se justifica la identificación del conocimiento con la acción. En la afirmación del pensador estadounidense que sigue se reconoce con claridad que en el aprendizaje están comprometidas las facultades sensoriales y particularmente las manuales: ${ }^{25}$

Cuando bajo la influencia de una concepción escolástica del conocimiento [que ignora todo lo que no sean hechos y verdades científicamente formulados] la educación deja de reconocer que la materia de estudio primaria o inicial existe ya como materia de un hacer activo, que exige el uso del cuerpo y el manejo del material, entonces la materia de enseñanza se aísla de las necesidades y propósitos del alumno, y llega a ser así algo que debe memorizarse y reproducirse cuando se pide.

Y después se reproduce una de las fórmulas mágicas de este movimiento, la de «aprender haciendo». La expresión, que también había utilizado Cossío,26 enfatiza el interés de los conocimientos adquiridos mientras se opera y manipula con el material directamente. En la atención dedicada a esta realidad lo que Dewey desea mostrar es la relación íntima que se establece con el objeto cuando este forma parte de nuestra proximidad y cercanía, una correspondencia inexistente con las formas abstractas, remotas y frías. ${ }^{27}$

\footnotetext{
24 Dewey, Democracia y educación, 159.

25 Dewey, Democracia y educación, 161; John Dewey, Experiencia y educación, ed. de Javier Sáenz Obregón (Madrid: Biblioteca Nueva, 2010), 102-103.

26 Precisamente en la conferencia impartida en 1905 en El Sitio de Bilbao y publicada con el título «El maestro, la escuela y el material de enseñanza» el siguiente año. Allí se decía: «Y, sobre todo, y esto es lo más importante para el niño en la escuela primaria, al construirlos les habrá quitado el misterio, habrá intimado con ellos, penetrado en las leyes naturales que demuestran; habrá, no aprendido, sino hecho, fabricado y adquirido la potencia de seguir fabricando. He aquí uno de los grandes principios restaurados por la educación contemporánea: el aprendizaje por la acción, el learning by doing del pueblo americano», Manuel B. Cossío, El maestro, la escuela y el material de enseñanza y otros escritos, ed. de Eugenio Otero Urtaza (Madrid: Biblioteca Nueva, 2007), 66.
}

27 Dewey, Democracia y educación, 162. 
Esta manera de apreciar las realidades materiales se inserta en su concepción de la democracia, ya que estos conocimientos se complementan con las experiencias que compartimos con los demás para formar empresas comunes; así pues: lo que los demás nos comunican nos concierne «realmente y por tanto toda noticia sobre ellas que nos ayude a tratar las cosas que tenemos a mano cae dentro de la experiencia personal». ${ }^{28}$ Lo contario es «trabajo memorista», "preocupación atomística por los hechos» o «meras palabras», si «lo comunicado no puede organizarse en la experiencia existente del alumno».29

En este contexto, la tarea del educador es asegurar, empleando las materias que forman parte del programa, un ambiente adecuado que estimule a los estudiantes para que estos tengan la disposición intelectual y emocional apropiada para los cometidos señalados. ${ }^{30}$

Dentro de esta forma de entender el aprendizaje, la práctica del juego ocupa un lugar destacado. ${ }^{31}$ Una propuesta que no obedece a la pretensión de aliviar el aburrimiento y la tensión derivada del trabajo, sino a un cometido con un mayor alcance. Son motivos de tipo intelectual y social. Para Dewey, se ha reconocido el valor que tienen las tendencias, puestas de manifiesto con el juego, a explorar, a manipular materiales, a construir y expresar las emociones. De esta manera también se reduce la distancia entre la vida en la escuela y fuera de ella.

\section{INDUSTRIA Y APRENDIZAJE MANUAL}

Los mensajes de Dewey dirigidos a impulsar el aprendizaje activo, con una favorable acogida en España dentro de determinados sectores renovadores, eran indicaciones generales que admitían varias interpretaciones, desde la libertad en la fabricación de materiales en el aula y la promoción de los trabajos manuales en talleres, que existían por ejemplo en las escuelas

\footnotetext{
28 Dewey, Democracia y educación, 163 y Dewey, Experiencia y educación, 97.

29 Dewey, Democracia y educación, 164.

30 «Cuando la educación se basa en la experiencia y se considera a la experiencia educativa como un proceso social, la situación cambia radicalmente. El maestro pierde la posición de amo o dictador exterior y adopta la de guía de las actividades del grupo» (Dewey, Experiencia y educación, 99); véase Dewey, Democracia y educación, 158 y Dewey, Experiencia y educación, 87-88.
}

31 Dewey, Experiencia y educación, 169. 
normales, hasta las demostraciones mixtas, en las que participaba el docente y el estudiante. Es difícil determinar la extensión de estas prácticas. En la Segunda República da la impresión de que la escuela activa parecía más un proyecto precedido de algunos ensayos, como ya se había apuntado, que una realidad mínimamente consolidada. Había quienes en 1930 se quejaban de la pervivencia de los métodos anticuados en la enseñanza de las ciencias. ${ }^{32}$ También existían miradas escépticas hacia las posibilidades de su aplicación, alegando que eran inviables en clases con un número de alumnos que oscilaba entre cincuenta y setenta. ${ }^{33}$ Unas apreciaciones críticas que también se extendían a la enseñanza secundaria. ${ }^{34}$

Pero estas evidencias no nos ofrecen un cuadro realista de la extensión de los procedimientos de la escuela activa. En este trabajo se defiende la propuesta de estudiar, con el fin de contar con una estimación más ajustada de ese fenómeno, la intervención de la industria del juguete instructivo en la educación, si bien asumiendo previamente que en este caso su acción se extiende principalmente, aunque no exclusivamente, a los entornos no formales. El impulso que reciben estos métodos no se realizaba siguiendo los patrones y condiciones de la escuela formal, porque obviamente el agente promotor es una empresa comercial, hecho que además condicionaba, como veremos, el significado que atribuían a los valores que incorporaban a sus mensajes.

La entidad de referencia que se analizará para comprobar el grado de extensión del precepto de la instrucción práctica y activa es la compañía Meccano, radicada desde 1901 en Liverpool, y en particular su proyección en España por medio de la publicidad y otros documentos en el decenio 1926-1936, un indicador valioso para evaluar la difusión de sus productos y discurso en la sociedad de la época.

\section{Mundo Meccano}

El nombre que precedió al de Meccano, la fábrica de juegos de construcción más importante por su volumen de negocio a principios del

\footnotetext{
32 R. O. Frink, "El valor educativo de las ciencias y su papel en una enseñanza moderna», Acción naturista 141 (septiembre, 1930): 273-280.

33 s/a, Escuelas de España 3 (marzo, 1934): 38-39.

34 s/a, «Notas. Reformas en la enseñanza», Escuelas de España 9 (septiembre, 1934): 34-36.
} 
siglo veinte, ${ }^{35}$ fue Mechanics made Easy, en 1901. Con la alusión a la facilidad en el eslogan que incorpora la firma se insinuaban diferentes asociaciones. Por una parte, se invocaban las imágenes de simplicidad y accesibilidad de las piezas que formaban parte de los estuches que vendía. Por la otra, se advertía sobre la sencillez de uso. Ambas connotaciones eran relevantes para asegurar la aceptación del nuevo entretenimiento en el mercado, en abierta competencia con los artilugios clásicos prefabricados. De esta manera, se aludía a que los kits consistían en un número de partes mínimas y básicas que componían la estructura de cualquier máquina (basado en el principio de que toda máquina compleja puede reducirse a máquinas simples). A este significado se sumaba el de que esas partes eran elementos estandarizados manejables por su tamaño y forma y que consecuentemente podían combinarse y ensamblarse de manera ilimitada, aunque existieran modelos orientativos.

El concepto de simplicidad y sencillez, que aquí se incorpora como estrategia persuasiva, se reclamaba con insistencia en propuestas educativas que estaban dirigidas a facilitar el aprendizaje de la ciencia. La tradición que inicia entre otros el divulgador Gaston Tissandier con sus Récréations scientifiques ou l'enseignement par les jeux, publicado en 1880, ${ }^{36}$ llega hasta el mencionado José Estalella, quien publicó en 1918 Ciencia recreativa (donde menciona al propio Tissandier). El autor francés defendía en la introducción del texto la conveniencia de emplear objetos sencillos e «insignificantes» para aprender los principios del calor, la electricidad y la óptica. Este atributo los hacía más familiares y por tanto más accesibles, una ventaja que se destaca en el discurso institucionista de Cossío; en la segunda edición de 1911 del Nouveau dictionaire de pédagogie (obra en 4 volúmenes dirigida por Ferdinand Buisson); en Dewey (1916) y, por señalar un ejemplo representativo más, en las posiciones del profesor vinculado al Museo Pedagógico Nacional, Edmundo Lozano, quien afirmaba que eran más valiosos los útiles simples que se encuentran en una cocina que los múltiples aparatos complejos adquiridos a las compañías de fabricación de instrumentos. ${ }^{37}$

\footnotetext{
35 Keneeth D. Brown, The British Toy Business: A History since 1700 (Londres: The Hambledon Press, 1996), 120-122.

36 Versión española: Recreaciones científicas (Madrid: Cárlos Bailly Baillière, 1882)

37 Edmundo Lozano, «Pedagogía de las ciencias físico-químicas», BILE, XXXVI, 631 (1912): 289293.
} 
Desde 1919, en España y Portugal el agente oficial de Meccano fue José Palouzíe Serra, cuya sede estaba en Barcelona. ${ }^{38}$ A partir de ese momento comienza la expansión comercial y publicitaria de la marca en la península. En esos actos de proyección se emplean mensajes que vinculan los productos con determinados valores. El que estamos ahora examinando aparece en el cuerpo del texto, por otra parte extenso, como veremos, de los primeros anuncios (véase la figura 1). ${ }^{39}$ En un momento del mismo se afirma que «Construir con Meccano es deliciosamente fácil é infinitamente encantador. No se necesita ninguna habilidad ó estudio»..$^{40}$ El resto del texto incorpora otros tópicos ya familiares en la pedagogía renovadora que iremos analizando a continuación. Como modelo inicial de referencia se empleará el reclamo publicitario al que pertenece la cita anterior, publicado en el diario La Esfera en el año 1920, que representa un patrón sobre el que se irán introduciendo mínimas variaciones en los años siguientes, finalizando la etapa que se revisará en el año 1936.

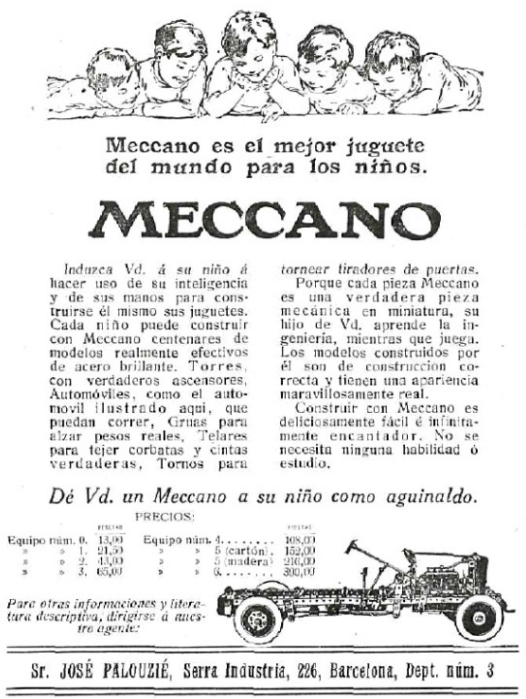

Figura 1. La Esfera, 20 de noviembre de 1920, 4.

\footnotetext{
38 En 1930 consiguió la licencia de fabricación en España.

39 En la obra de Juan Bordes (Historia de los juguetes de construcción, 44-45 y 106-107) se destaca la importancia de analizar las cubiertas de las cajas de estos juegos, así como las imágenes de los manuales y la publicidad para obtener información sobre cuáles eran los destinatarios de los entretenimientos y los patrones sociales que reproducían.
}

40 La Esfera, 20 de noviembre de 1920, 4. 
¿Cómo vender una pieza de ingeniería en miniatura como un entretenimiento alegre para un joven? El desafío para los publicistas era presentar una tarea compleja como un juego inocente acompañado de contribuciones a la formación y a la organización eficaz del tiempo. En el diseño del anuncio se recrean y ordenan estos elementos. Así, se presenta el grupo de niños en la parte superior deleitándose, la alusión al juguete en las primeras líneas, el protagonismo gráfico de la marca, con letras en negrita de cuerpo mayor, el extenso texto persuasivo -representativo del estilo de las agencias norteamericanas- y el resultado del objeto admirado -un vehículo-, ya construido, en la parte inferior, al que nos dirige la mirada de los niños.

Ya se ha destacado que el movimiento de la pedagogía activa situaba el foco de su interés en la adquisición de habilidades corporales. Este valor en la versión comercial de Meccano se reconoce en la primera línea del texto: «Induzca Vd. á su niño á hacer uso de su inteligencia y de sus manos para construirse él mismo sus juguetes». ${ }^{41}$ En este caso se recurre a una fórmula en la que se combina el cerebro y la mano, algo apreciado por los promotores de la escuela mencionada.

Seguidamente se menciona recurrentemente otro de los valores de un movimiento dominado por el pragmatismo, que es el de fomentar la competencia práctica del aprendiz mediante el ejercicio de la construcción manual. En el marco del anuncio se asegura que «Cada niño puede construir con Meccano centenares de modelos realmente efectivos» o que «Los modelos construidos por él son de construcción correcta y tienen una apariencia real». Se insiste por tanto en que el propósito primordial de este juego es esa dimensión creativa implícita en el proceso de construcción.

Sumándose a los conceptos citados, el último valor que se pone de relieve es el del juego, en tanto deleite o disfrute de una actividad cuyo fin está dentro de sí misma. Aquí además se vincula este pasatiempo a la formación del joven, conformando la fórmula, convertida ahora en eslogan, que identifica las propuestas de los movimientos activos: la horaciana podesse et delectare o en la versión del anuncio: «Su hijo de Vd. aprende la ingeniería mientras juega».

41 También, muy importante, se fomenta la autonomía. 


\section{Evolución del mensaje}

Los componentes del mensaje de la campaña fundacional se van repitiendo, si bien se incorporan matices y se producen variaciones en los iconos que lo acompañan. Así, para enfatizar la interacción con el modelo que se construye, se añade la imagen de un niño que está haciendo unos últimos ajustes con su mano izquierda (véase la figura 2). Al lado, aparece una niña que asiste de pie complacida al espectáculo de la construcción mecánica. ${ }^{42}$ La novedad aquí es la intervención táctil del niño, que contrasta con la visual y contemplativa de la niña.

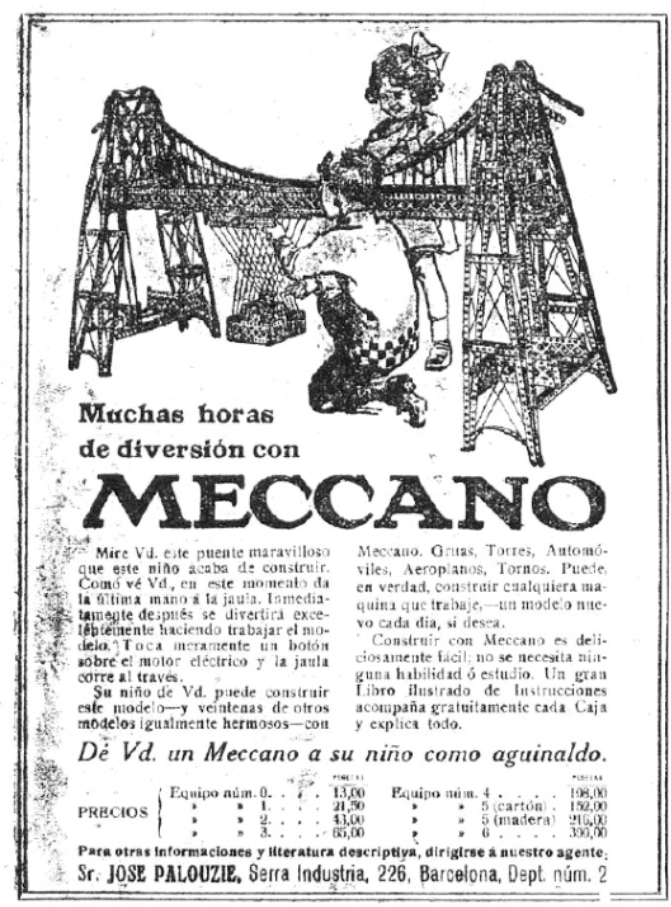

Figura 2. Mundo gráfico, 17 de noviembre de 1920, 25.

En un anuncio del mismo período publicado, como el primero, en $\mathrm{La}$ Esfera se refuerza la asociación entre la diversión y el movimiento, la idea de los niños que disfrutan saltando y corriendo, e intercambiando objetos, aunque en este caso con figuras interdependientes: "Los niños quieren apasionadamente un objeto que 'pueda moverse', un objeto que

42 Mundo gráfico, 17 de noviembre de 1920, 25. 
puedan ellos mismos construir y demoler. Esto explica la popularidad de Meccano» (véase la figura 3). ${ }^{43} \mathrm{Al}$ final, en un párrafo aparte se recuerda una versión de la simplicidad -el valor ya aludido- en la que se subraya la accesibilidad de un material que no precisa orientaciones previas porque es intuitivo: «No se necesita ninguna habilidad o estudio: el genio se ha puesto en las piezas al inventarlas». Todo ello además contribuye a potenciar la autonomía del niño. En el apartado iconográfico, el niño, ahora en solitario, se dispone a hacer ajustes en un modelo de la Torre Eiffel, símbolo fácilmente reconocible para el consumidor europeo.

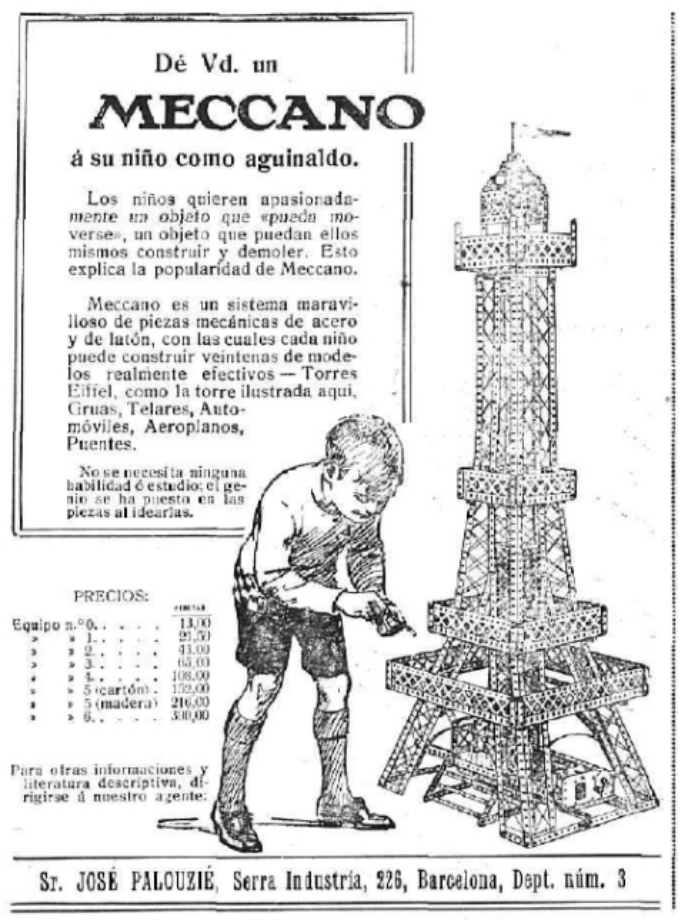

Figura 3. La Esfera, 11 de diciembre de 1920, 4.

La introducción de complementos, como la publicación de un manual de consulta, es un pretexto para nuevos diseños publicitarios. ${ }^{44} \mathrm{En}$ la imagen del anuncio el joven está tumbado en el suelo, ojeando el

\footnotetext{
43 La Esfera, 11 de diciembre de 1920, 4.

${ }_{44}$ Nuevo mundo, 15 de diciembre de 1922, 5.
} 
«nuevo libro» y rodeado de piezas; junto a él un modelo de grúa ya prácticamente finalizado (véase la figura 5). Dos años más tarde sorprende un diseño publicitario en el que, además de anunciarse la publicación mencionada, el modelo ha adquirido unas proporciones no de un juguete de dimensiones manipulables, sino de una construcción real (véase la figura 4). ${ }^{45}$ Se quiere así mostrar toda la potencialidad que en las manos de los niños tienen los dispositivos que se comercializan.

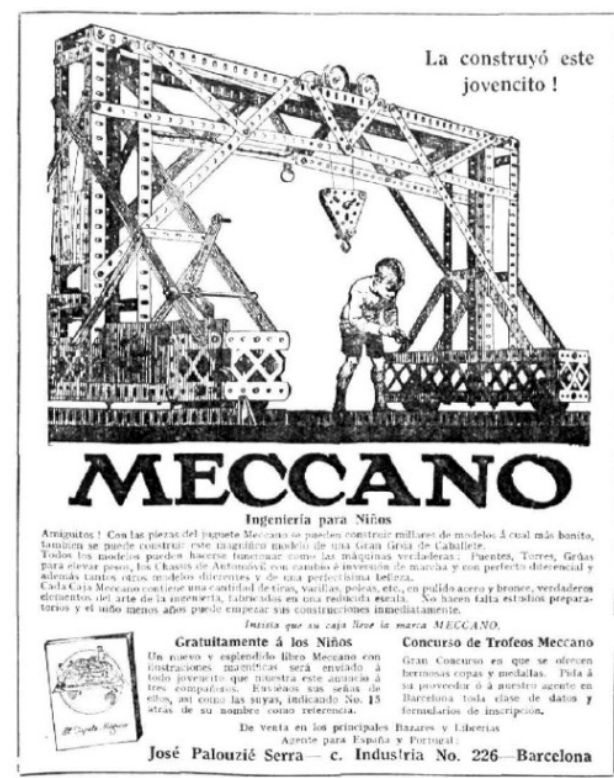

Figura 4. Nuevo mundo, 15 de diciembre de $1922,5$.

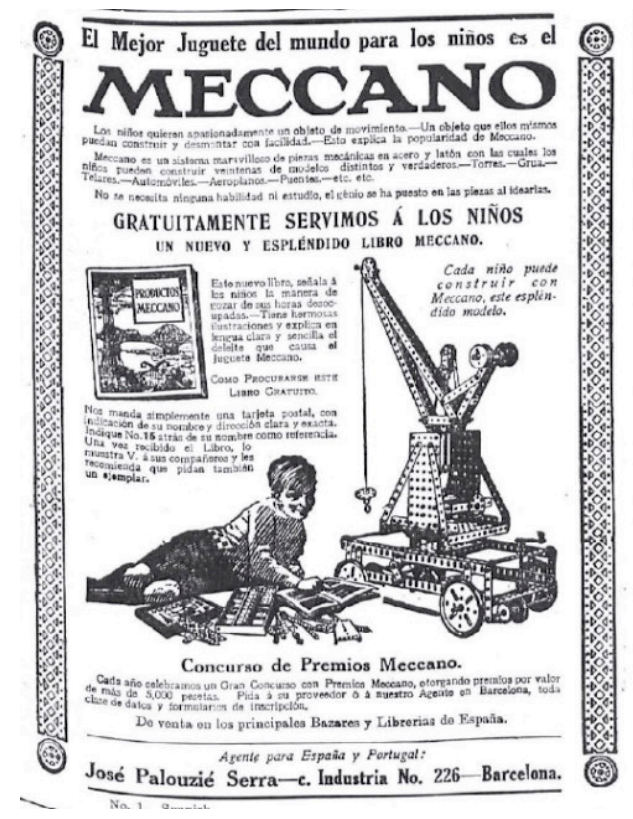

Figura 5. Nuevo mundo, 21 de noviembre de 1924, 39.

En el año 1926 se presenta como una innovación, acompañada de la retórica de la primicia, la introducción de los colores en las piezas: «Muchas importantes piezas del Meccano están ahora esmaltadas en colores rojo y verde...». ${ }^{46}$ Con este motivo, el año siguiente por primera vez se añade la figura paterna, que disfruta por detrás de su hijo cómo este ojea el manual en el que supuestamente observa la nueva apariencia de los modelos: «¡Mira Papá! ¡Qué Coloreado Está!», reza el mensaje de cabecera (véase la figura 6).

\footnotetext{
45 Nuevo mundo, 21 de noviembre de 1924, 39.

46 Mundo gráfico, 15 de diciembre de 1926, 30.
} 


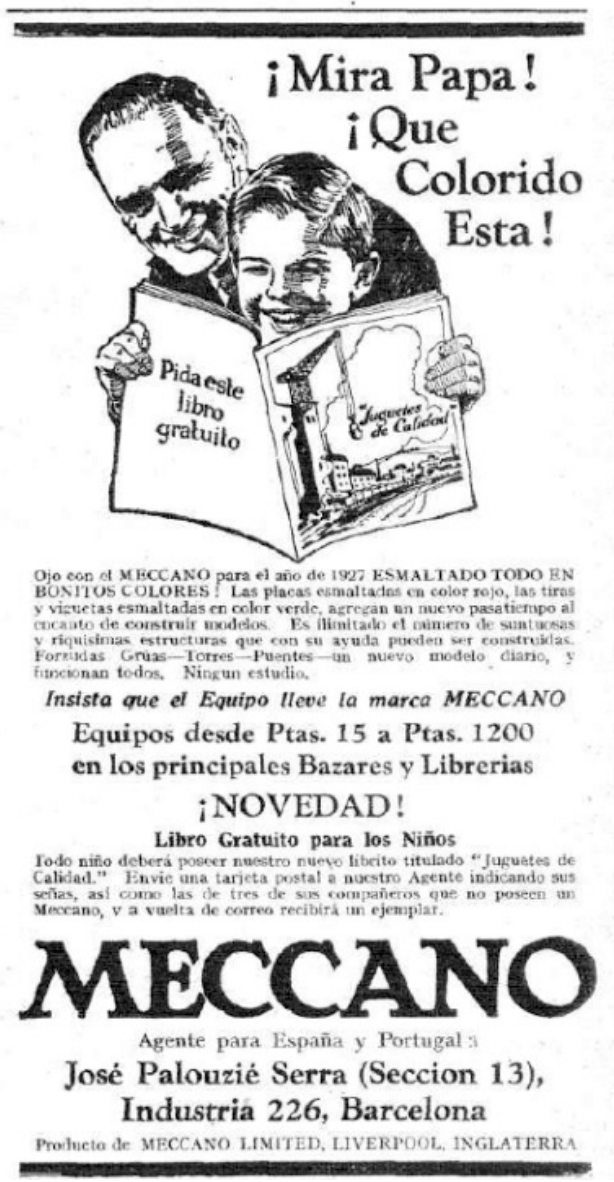

Figura 6. La novedad, Mundo gráfico, 14 de diciembre de 1927, 26.

Hasta ahora los signos que han ido conformando los diferentes reclamos publicitarios representaban a un consumidor joven, de entre $10 \mathrm{y}$ 16 años, preferentemente masculino ${ }^{47}$ y de clase acomodada (las colecciones de piezas eran en general de un precio elevado para un salario medio). ${ }^{48}$ Al final del período considerado sin embargo se emplea una

47 El consumidor joven masculino se construye mediante su asociación con tareas tecnológicas y
emprendedoras, alejado de la imagen emotiva que conduce supuestamente las adquisiciones feme-
ninas, Lisa Jacobson, «Manly Boys and Enterprising Dreamers: Business and the construction of the
Boy Consumer, 1910-1930», Enterprise and Society 2, no. 2 (2001): 225-258, 227-229.
48 En un breve relato satírico titulado «El papá laico», publicado en La Nación (7 de enero, 1936,
14), en el que un padre ofrece a su hijo que elija el juguete que desea como regalo de Reyes; al 
ilustración que podría interpretarse de dos formas diferentes. En sendos anuncios publicados en Crónica ${ }^{49}$ y Mundo Gráfico ${ }^{50}$ se identifican, en la imagen, dos figuras que podrían corresponder a la madre y a la hermana de un joven que está frente a una construcción mecánica, y a quien están intentando desplazar de su entretenimiento para o bien participar en el juego o bien para simplemente apartarle de su ensimismamiento. Las evidencias disponibles no nos permiten resolver esta cuestión (véase la figura 7).

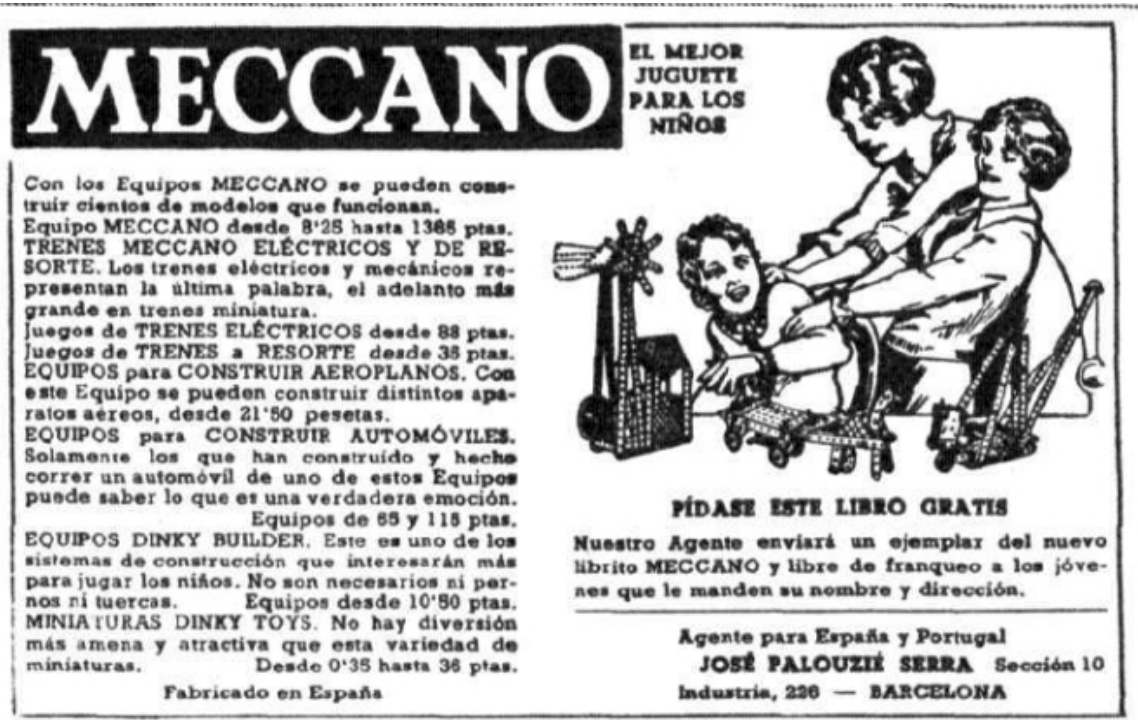

Figura 7. El cambio de imagen, Mundo gráfico, 25 de diciembre de 1935, 43.

Desde el principio, junto a los valores mencionados, se conforman unos ideales en los que la actividad lúdica ejercida cuenta con una proyección en la sociedad del momento. En el anuncio de la revista Alrededor del Mundo, de 1925, se manifiesta con claridad la vinculación existente

señalar uno que ve en un escaparate, «el padre, como no es ningún fantástico rey mago, tiene que recoger las velas de su generosidad y aducir reparos económicos: Esa meccano es carísima; juguete de rico». En la biografía del fundador de la compañía se afirma que los primeros modelos de la marca eran muy caros, Anthony McReavy, The Toy Maker. The Life and Times of Inventor Frank Hornby (Londres: Ebury Press, 2007), 108.

491 de diciembre de 1935, 31.

50 4 de diciembre de 1935, 43. 
entre ese mundo autónomo y personal del deleite infantil con el mundo ingenieril: «Amiguito! ¿Por qué razón tantos jovencitos de tu edad están tan «aficionados al Meccano? Porque los modelos que se pueden construir son en miniatura las verdaderas estructuras del arte del ingeniero» ${ }^{51}$. El anuncio muestra detalles de los ensamblajes para insistir visualmente en el grado de precisión de las piezas manejadas.

A estos modos de participación contribuyó la creación de una nueva identidad entre los participantes en el juego: los Meccaninfos. Las imágenes fomentadas que se reflejaban en la publicidad asociaban la disposición de los kits con el éxito y la construcción del futuro, así como con el fomento de la ambición, la precisión, la salud física y moral y la iniciativa. ${ }^{52}$ Para estos cometidos se elegían mensajes como «Los meccaninfos de hoy serán los ingenieros del mañana» y «Los Meccaninfos de hoy construirán los aviones de mañana» (véase la figura 8). ${ }^{53} \mathrm{El}$ gremio de Meccano consistía, como se expresa en la propaganda, ${ }^{54}$ en:

Todos los poseedores de una caja de Mecano deben asociarse al gremio de Mecano. Es una organización mundial, que comenzó como una demanda de los Meccano boys [Meccaninfos]. Su primer objetivo es poner en contacto a los chicos y hacerlos sentir que son todos miembros de una gran hermandad, donde tratan de ayudarse unos a otros y de obtener lo mejor de la vida. Sus miembros están en contacto permanente con la central, ofreciendo noticias de sus actividades y siendo guiados en sus aficiones e intereses.

De esta forma el gremio, como el colectivo de los «Boys Scouts», alude a «un pasado idealizado y a una creencia en el progreso futuro. En 1932, los socios del Gremio Meccano habían llegado a 100.000 chicos en todo el mundo».55

\footnotetext{
51 Alrededor del mundo, 12 de diciembre de 1925, 21.

52 Lynne Vallone, Big and Small: A Cultural History of Extraordinary Bodies (New Haven y Londres: Yale University Press, 2017), 209-211.

53 «Los pilotos que realizarán los raids aéreos de mañana son los Meccaninfos de hoy, ya que seguirán los principios de la verdadera ingeniería moderna en la construcción de modelos con los mecanismos más maravillosos del mundo» (Mundo Gráfico, 12 de diciembre de 1928, 39).

54 Meccano. Instructions for N. ${ }^{\circ} 1$ Outfit, 1937.

55 Vallone, Big and Small, 211.
} 

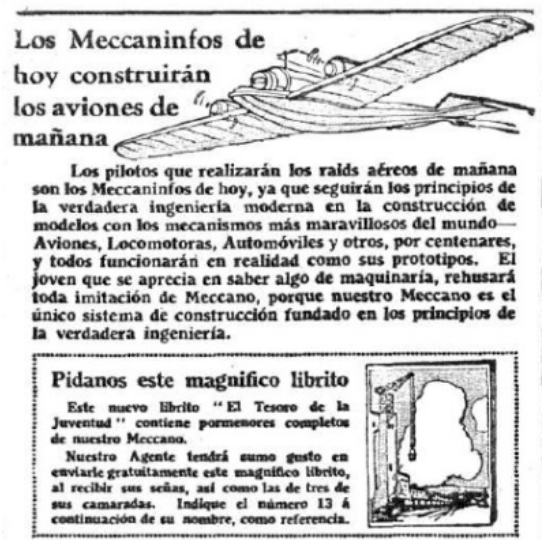

Equipos desde Ptas 12.50 a Ptas 1100.00 en los principales Bazares y Librerias

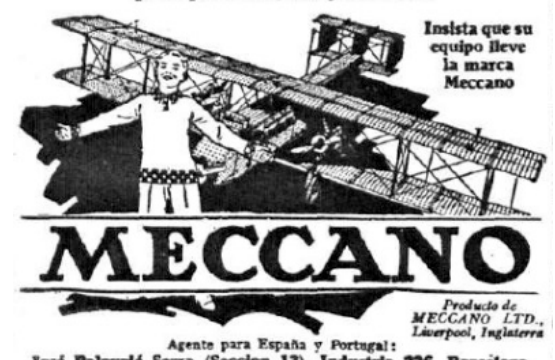

Joué Palouade Serra (Seccion 13), Industria 226, Barcélona

Figura 8. La construcción del futuro y la identidad del grupo, Mundo gráfico, 12 de diciembre de 1928, 39.

Junto a estos medios, otro de los instrumentos que sirvió tanto para el fomento de la industria como para la consolidación de valores fue Meccano Magazine, que se inició como un soporte dedicado a la propaganda, pero en los años 1920 se convirtió en una revista bien ilustrada con artículos dedicados a la difusión tecnológica, y en menor medida a la científica, geográfica y antropológica, que alcanzó una circulación de 70.000 ejemplares. Peter Bowler, en su estudio sobre la publicación, ha señalado que la ideología promovida por los editores tenía un sesgo de género masculino, como único colectivo interesado en la técnica, y una aspiración imperialista, subrayando la coincidencia de intereses de la Corona británica y el progreso tecnológico. ${ }^{56}$

56 Peter Bowler, «Meccano Magazine: boys' toys and the popularization of science in early twentieth-century Britain», BJHS Themes 3 (2018): 130. 


\section{DIFUSIÓN DEL MENSAJE Y MEDIACIONES}

La prensa española, tanto diarios como revistas, en la que incluimos las publicaciones infantiles y juveniles, sirvió de soporte desde el año 1920 a la estrategia publicitaria de Meccano. A los ejemplares aludidos hay que sumar otros de amplia circulación, como El Heraldo de Madrid, El Imparcial, ABC, La Vanguardia, Pinocho... Durante la década de 1920 se aprecia una importante presencia de anuncios, que varían ligeramente en el diseño, pero siguiendo la estructura de los modelos aludidos. Inmediatamente después, probablemente por la influencia de la depresión de 1929, se observa una reducción destacada del despliegue publicitario, produciéndose una leve recuperación a finales de 1933, y a lo largo de los años 1934 y 1935. En total, en el período 1924-1936, en el diario $A B C$ se insertaron 48 anuncios y en La Vanguardia, 18.

Meccano también accedió e intervino en el mercado de la educación formal. Las casas españolas de material escolar reservaron un espacio para los juegos de construcción-instrucción en su oferta. ${ }^{57}$ A esta circulación contribuyó, por ejemplo, el comercio barcelonés Material Escolar y Científico, uno de los más activos en ese sector. ${ }^{58}$

Las evidencias de la contribución de estos establecimientos a la red de distribución de los nuevos productos proceden igualmente de los anuncios, esta vez enmarcados en la campaña navideña y, por tanto, con atributos especiales. En esos momentos los mensajes no tenían solo una connotación informativa, dedicada a identificar la casa, sino que incorporaban un sesgo emotivo, como se puede comprobar en el anuncio reproducido (véase la figura 9). En él se aprecia el dominio del término «reyes» entre admiraciones dobles y un cuerpo de letra diferente al del resto del texto. En este, además, se alude a la disponibilidad de los siguientes tipos de productos: Mecano, radio (probablemente para público infantil también), y en general a «juguetes instructivos». El reclamo

\footnotetext{
57 En el Instituto Lope de Vega se ha encontrado un folleto de Meccano, no datado, que corresponde aproximadamente a 1935 .

58 Sobre la importancia y el interés de los catálogos de las casas comerciales de material educativo como fuente de estudio histórico, véase José Damián López Martínez et al., «Patrimonio, cultura material e innovación docente: Propuestas y experiencias», Educació i Història: Revista d'Història de l'Educació 26 (2015): 106-113.
} 
con un formato similar se repitió el 1 (duplicado en la misma edición en catalán, p. 18), 2, 3 y 5 de enero, así como en el año 1927.

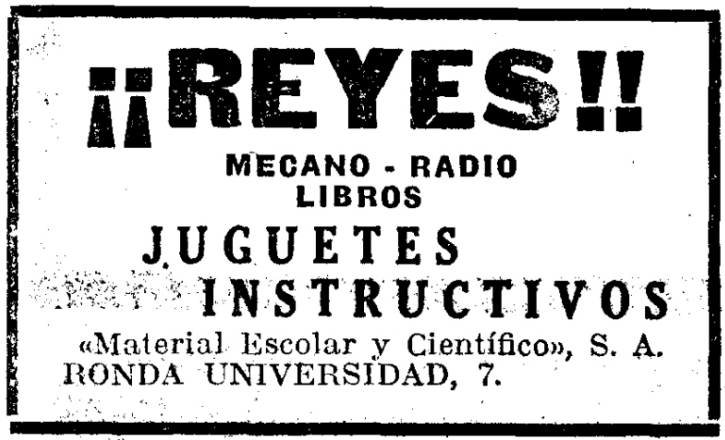

Figura 9. La Vanguardia, 31 de diciembre de 1925.

En esta posición y representando un papel similar se encontraba la casa Espasa-Calpe, ubicada en Madrid. La sección de material de enseñanza inició su actividad en 1931 y tres años después publicaba su primer catálogo. El anuncio mostrado a continuación (véase la figura 10), el único conocido con la mención explícita a Meccano, confirma estos vínculos con las fábricas internacionales.

\section{SI QUIERE QUE SU HIJO SE

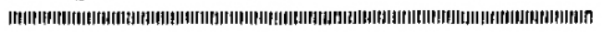 INSTRUYA MIENTRAS JUEGA

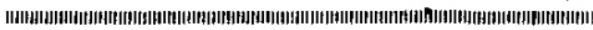 \\ LOS MEJORES REGALOS SERAM \\ CAJA DE CONSTRUICCION. que ínician at nino en la electri. cidad y el magnetismo. \\ CONSTRUCCIONES MECCANO, MICROSCOPIOS, ESFERAS TERRESTRES, FERROCARRILES ME- : : : : CANICOS Y ELLCCTRICOS, CUENTOS : : : : \\ Vean la Exposición que de material de ensenanza tiene instalada \\ espasa CALPE, S. A. BARQUiLLO, núm. 23 \\ TELEPONO 23.688, MADRID}

Figura 10. La Libertad, 4 de enero de 1936. 
Vuelven en este caso a emitirse los mensajes en fechas con connotaciones emotivas -víspera de Reyes-, y por medio de mensajes-eslogan que apelan a un consumidor que debe creer en el aprovechamiento del tiempo libre para la formación y el futuro de su hijo. Un concepto asociado a la idea del ocio positivo y no malgastado que procedía de la mentalidad anglosajona y puritana. Con esta premisa se construye un texto en el que el titular tiene la forma de un condicional donde solo se escribe una parte -la subordinada- para que se complete con la información del cuerpo del anuncio. Mediante este artificio retórico, la mirada se fija en la parte superior, recorre en el orden gramatical las palabras y se dirige a la relación de productos ofrecidos, donde se mencionan la caja de construcción, para la electricidad y el magnetismo y, junto a otros entretenimientos, el Meccano destacado en negrita. En la secuencia «Si quiere que su hijo se instruya mientras juega» hay tres elementos, «hijo», «instruya» y «juega» con vínculos evocadores de diferentes imágenes, según se precisa en la siguiente tabla, cuyo cometido es persuadir al adulto.

\begin{tabular}{|l|l|}
\hline Elemento & Función y asociaciones \\
\hline Hijo & $\begin{array}{l}\text { Responsabilidad paternal. } \\
\text { Destinatario de juguetes. } \\
\text { El niño como protagonista representa ternura, ingenuidad } \\
\text { y simpatía. } \\
\text { Selección del colectivo/sexo destinatario del producto. }\end{array}$ \\
\hline Instrucción & $\begin{array}{l}\text { Educación, formación, comunicación de reglas de } \\
\text { conducta... }\end{array}$ \\
\hline \multirow{3}{*}{ Juego } & $\begin{array}{l}\text { Diversión, entretenimiento sin esfuerzo, ocio... La } \\
\text { combinación con «instrucción» remite a la antigua } \\
\text { sentencia de Horacio, repetida en la pedagogía: instruir } \\
\text { deleitando.59 }\end{array}$ \\
\hline
\end{tabular}

Las casas no solo actuaron como agentes distribuyendo los productos originales, sino que confeccionaron o vendieron modelos destinados a las escuelas que imitaban los patrones modulares de Meccano, si bien

\footnotetext{
59 Véase la parte histórica en María de Borja i Solé, El juego como actividad educativa. Instruir deleitando (Barcelona: Universitat de Barcelona, 1984), «Primera parte», 19-33.
} 
con materiales diferentes más económicos. En el catálogo de Material Escolar y Científico (c. 1930, 8)60 leemos lo siguiente: en el ítem 490: «Caja Meccano con su librito correspondiente para efectuar construcciones metálicas, como ejercicio de imaginación y habilidad». Estas piezas estaban en la Sección IV «Trabajos manuales, juguetes y juegos educativos». Apartado en el que además se ofertan los siguientes dispositivos: «430. Material educativo para la escuela activa» (p. 7);61 «637 Caja con elementos planos de madera, de colores distintos, agujereados por el centro, que permiten unirse utilizando las madejas de hilo que lleva el estuche, pudiéndose hacer infinidad de formas planas»; «7752 Cajas modernas $\operatorname{Kosmos}^{62}$ de física y química», a la que se añade la siguiente explicación:

Conteniendo una serie de aparatos y piezas perfectamente estudiadas para hacer un sinfín de experimentos de física y química. Estas cajas destinadas a la enseñanza primaria en sus grados elemental y superior y a la media, ofrecen no solo al maestro la posibilidad de poseer un pequeño conjunto de material experimental, que sin ninguna dificultad hace ver a los alumnos lo más

\footnotetext{
60 Material Escolar y Científico, Catálogo general A-38 de material de enseñanza. Barcelona [c.1930].

61 Un estudio de la revista argentina La Obra pone de manifiesto los vínculos entre los presupuestos de la escuela activa y el uso de dispositivos de Meccano en la confección de las demostraciones, véase Agustín Adúriz Bravo «La propuesta didáctica del movimiento de la Escuela Nueva para la física: Argentina, 1921-1928», Revista Latinoamericana de Estudios Educativos (México) Vol. XXIX, no. 4 (1999), 151-160 [Consultado el 16 de abril de 2020]. Disponible en: https://www.redalyc.org/ articulo.oa?id=270/27029405
}

62 Los inicios de esta línea productiva, que imita los métodos de Meccano, se sitúan a comienzos del siglo veinte, cuando los dueños de la compañía crearon la Gesellschaft für Naturfreunde con la finalidad de reunir a personas interesadas en la educación y la naturaleza. En 1904 se lanzó la revista mensual Kosmos. Handweiser für Naturfreunde, en la que se describían y discutían montajes experimentales. Unos cuantos años más tarde, ya en la década de 1920, es cuando se confeccionan en la división educativa de la firma las primeras cajas de experimentos, siguiendo las directrices del profesor suizo Wilhelm Fröhlich (1892-1969), que había estudiado física y química en Ginebra y Berna. Entre 1921 y 1937 la firma produjo diversas Kosmos- Baukästen, es decir, cajas de construcción dedicadas a la electricidad (1921), la óptica (1923), la mecánica (1924/25), la química (1927), la radio (1930), la astronomía (1928), geometría (en torno a 1928), biología (1935), agricultura (1936), microscopía (1936) e ingeniería (en torno a 1937). Estas composiciones estaban pensadas para usos individuales y domésticos, en entornos, en principio, no guiados, pero también se diseñaron para centros educativos (Viola van Beek, «Experimental spaces outside the laboratory - Experiment kits and instruction manuals around 1900». The Virtual Laboratory, 2009, disponible en http://vlp.mpiwg-berlin.mpg.de/references?id=art73). De hecho, se sabe que el Instituto de Enseñanza Secundaria de Cáceres adquirió cuatro cajas de física y química, véase Cristina Redondo Castro, «La segunda enseñanza pública en Extremadura, 1900-1936» (Tesis doctoral, Universidad de Málaga, 2018), 137. 
importante de las ciencias físicas químicas, sino que tienen la inmensa ventaja pedagógica de que el alumno se construye por si mismo los aparatos para hacer sus experimentos [...].63

Así, en el catálogo se presenta el discurso del experimento estandarizado, que según los patrones comerciales ofrece grandes ventajas, porque responde a las demandas de la educación activa, donde no solo los profesores imponen las directrices en los contenidos, sino que los alumnos cultivan su autonomía y las destrezas creativas propias de un aprendizaje científico.

En otro establecimiento con el mismo perfil, establecido igualmente en Barcelona, Dalmau Carles, Pla, se vendían unas piezas conocidas como Metabois, que según el catálogo del curso 1934-35, consistían en «Elementos para construcciones mecánicas en madera. Contiene 50 piezas perforadas de distintos tamaños» (con un precio de 16 pts.). ${ }^{64}$

Los establecimientos dedicados a material científico y pedagógico se convirtieron así en una vía de entrada de un nuevo concepto de objeto educativo, cuyos rasgos generales ya señalamos anteriormente, que se extiende desde Gran Bretaña, Estados Unidos y Alemania al resto del mundo a partir de los primeros años del siglo veinte, esta vez por medio de los canales comerciales.

La publicidad es un reflejo de valores sociales y también es una contribución a su refuerzo en el imaginario colectivo. Diversos indicios apuntan a que el juego de construcción había recibido a mediados de la década de los años 1920 y en la etapa republicana una respetable atención entre el público. Muchas personas pudieron ver por ejemplo el gran modelo de la Torre Eiffel construida por Meccano que se exhibía en la Exposición Internacional de Barcelona de 1929,65 donde había una sección dedicada al juguete instructivo. En el imaginario esta instalación se había anticipado ya en los anuncios de la marca, en los que, como en el de Nuevo Mundo (véase la figura 3) se veía a un niño inclinado dispuesto

\footnotetext{
63 Material Escolar y Científico, Catálogo, 62.

${ }_{64}$ Casa Editorial Dalmau, Carles, Pla, S.A., Catálogo de Material Escolar de la Casa Editorial Dalmau, Carles, Pla (Gerona-Madrid, curso 1934-1935), 231.

65 Actualmente se conserva en el Museo de Juguetes de Cataluña en Figueras.
} 
a realizar un ajuste en la réplica de la torre que supuestamente había fabricado.

En la prensa hay, además, algunas pruebas del grado de difusión de estos dispositivos, como el artículo aparecido en la revista ilustrada Alrededor del Mundo en 1925 (14 de noviembre, 12). La popular publicación estaba dedicada a las colaboraciones de tipo general, costumbrista, así como a las relacionadas con temas artísticos, de exploración, viajes, aventuras y también, con carácter divulgativo, a asuntos científicos y técnicos. La reseña de una página y tres columnas a la que nos referimos llevaba por título «La historia de un famoso juguete». Allí el responsable anónimo del texto señalaba uno de los rasgos distintivos del invento de Thomas Hornby, el fundador de Meccano: el hecho de ser un juguete que servía para crear otros juguetes, propósito conseguido por la disponibilidad de numerosas piezas intercambiables y desmontables. Añadía que actualmente el nombre de Meccano «es de reconocida fama en todos los países del mundo, pues significa el sin igual juguete universal del siglo». Después se elabora un relato heroico sobre los avatares que condujeron a la consolidación de la empresa. En conjunto, la colaboración sin firma más que una crónica de hechos puede considerarse una modalidad de texto publicitario por el que la revista recibió probablemente una compensación económica. Teniendo en cuenta la afirmación de que el «éxito de Meccano en nuestro país [España] fue extraordinario», se contemplarán otras evidencias menos sesgadas. ${ }^{66}$

En la revista mensual dedicada a la divulgación técnica El Constructor (septiembre de 1926, 56) se hace una versión de la noticia aparecida en Alrededor del Mundo sin que aparentemente hubiera una intención propagandística. En uno de sus apartados se dice:

¿Quién no se ha extasiado ante esos maravillosos «Meccanos» que nos permiten realizar construcciones maravillosas y no estáticas sino plenas de vida y movimiento? ¿Quién no ha sentido deseo de poseer uno de esos «Meccanos» para pasar las largas veladas del invierno, sobre todo esos domingos interminables para los que aún nos mantenemos sin haber sido atacados por la Radio?

\footnotetext{
${ }^{66}$ José Corredor, El juguete en España (Madrid: Espasa, 1999), 180-182.
} 
Hay dos artículos con pretensiones solo de añadir notas informativas sobre la industria del juguete en España, si bien contienen además datos reveladores. Uno de ellos pertenece al diario La Libertad (6 de enero de $1933,3)$ y el otro a Revista de Crédito (30 de mayo de 1935, 27). En el primero, a la pregunta sobre cuáles iban a ser los juguetes más demandados para los regalos navideños respondía que serían los aviones, los coches y los «meccano», aunque también se reconocía que los modelos de cinematógrafo infantil iban a tener éxito. En el segundo artículo se afirmaba que:

En Barcelona se fabrica un juguete científico y agradable, análogo al tan conocido Meccano; tal juguete es el Trix, ${ }^{67}$ conjunto de piezas con las que pueden construirse los modelos más variados de puentes, torres, etc., y que ha obtenido gran aceptación en el mercado, tanto por su interés como por su baratura.

El último artículo que se citará («Los pequeños inventores», $\mathrm{La} \mathrm{Luz}$, 12 de septiembre de 1933,14) menciona el «célebre Meccano y la fiebre constructora de aparatos en los tiempos heroicos de la radio» en una reflexión sobre el interés de estos juguetes para educar la imaginación. Porque «no todo tiene que ser imaginación», una facultad que por sí sola, sin conocimientos ni entrenamiento científico adecuado, según se reconoce en el texto, conduce a plantear quimeras y camelos.

Además de los indicios citados, la incorporación de los términos comerciales al lenguaje común es un signo de extensión de unas determinadas prácticas. De estos usos se encuentran igualmente evidencias en la prensa. ${ }^{68}$

\section{CONCLUSIONES}

A lo largo del texto se ha puesto de manifiesto que a la hora de contemplar la extensión de determinadas prácticas educativas y valores asociados a las mismas es importante añadir la información de las labores

\footnotetext{
67 Marca alemana creada en 1931 para competir con Meccano, cuyos principios de construcción basados en los sistemas modulares son semejantes a los de la fábrica inglesa.

68 Ejemplo: Generación «Meccano» (Victor de la Serna, El Sol, 27 de septiembre de 1931, 2).
} 
que tienen lugar fuera de las aulas, en particular, en el caso aquí estudiado, en los contextos domésticos.

En el trabajo se ha visto que estos dominios, el formal y el no formal, mantienen relaciones que se expresan, por ejemplo, en las finalidades que se atribuyen a los materiales que se emplean en las tareas educativas y lúdicas. Así, en la industria se observan influencias de los círculos educativos, pero a su vez en estos últimos se emplearon materiales diseñados por los fabricantes en principio para el juego y el entretenimiento, aunque siempre se añadía en las promociones la virtud instructiva que tenían.

Los valores que Meccano incorporó a su discurso persuasivo procedieron de círculos educativos en los que se estaban revisando los patrones de la enseñanza técnica y científica, un movimiento que aquí se ha denominado, por emplear un término genérico, enseñanza activa. De esta forma se fue construyendo una alternativa retórica a la «escuela tradicional/oficial», con sus métodos memorísticos, rutinarios y aburridos, que había que desmontar y que no eran del agrado del propio Hornby, según afirma su biógrafo. ${ }^{69}$ Esa reacción permitió la admisión de los referentes a los sentidos y al cuerpo para describir el proceso adecuado de aprendizaje. Algo que refleja muy bien la iconografía publicitaria de Meccano.

Aquí se han distinguido los siguientes componentes discursivos de las propuestas analizadas. En el reclamo publicitario se ha destacado el uso de la sencillez, con el significado tanto de accesibilidad como de simplicidad, entendiendo por este concepto que las piezas que los jóvenes tienen a su alcance permiten llevar a cabo múltiples y variadas construcciones, porque son, siguiendo criterios inductivistas, las unidades básicas de los mecanismos complejos que se pueden contemplar y admirar en los anuncios. Este sentido de la sencillez es compartido en los círculos de la escuela activa, si bien en este caso adquiere también la connotación de una dimensión que se opone a la realidad ya hecha, compleja e inabarcable de un artefacto ya fabricado.

69 McReavy, The Toy Maker, 50. 
A partir de la virtud mencionada los jóvenes podían ejercitar su disposición a la creatividad, manipulando con sus manos las piezas y ensayando diversas disposiciones y soluciones, otro de los atributos compartidos por los partidarios de la escuela participativa.

El concepto de juego en el proceso de aprendizaje está presente en los promotores de la enseñanza entendida como una actividad práctica (como Cossío, Estalella, Dewey...), y de igual manera forma parte de los mensajes de los fabricantes de las cajas de construcción y científicas. Se opone al sistema tedioso, repetitivo y planificado, carente de espontaneidad, de la escuela oficial, organizada esta última desde la autoridad hacia el estudiante, no a la inversa como se pretende.

Frente a la memoria, facultad denostada especialmente en los círculos renovadores de la enseñanza de la ciencia y de la técnica, se pretende potenciar la intuición. ${ }^{70}$ Los niños sin conocimientos previos ofrecen respuestas a los problemas que se plantean. "Construir es fácil», se repite continuamente; los niños pueden ir encontrando soluciones sin esfuerzo en la práctica constructiva. Los jóvenes se comportan así como los investigadores que llevan a cabo descubrimientos. ${ }^{71}$

También, en contra del cultivo de la facultad memorística, en los discursos examinados se fomenta una combinación de tareas: la observación atenta, la habilidad manual y la inteligencia (facultad aludida en la publicidad de Meccano). Pero es una inteligencia intuitiva, ${ }^{72}$ una competencia que explica las respuestas rápidas a los acertijos mecánicos que no proceden de conocimientos previos explícitos, sino tácitos. Una manera de actuar que aparentemente simula la de los ingenieros.

La defensa que se hace de la autonomía en el aprendizaje, llevada a cabo en la presentación de estos juegos, con los rasgos ya vistos, es igualmente una forma de desconfianza hacia la escuela oficial. El mensaje implícito en estos presupuestos era que mediante los dispositivos se fortalecían las prácticas autosuficientes y así se podía prescindir de los métodos anquilosados de la enseñanza rutinaria.

\footnotetext{
70 La intuición está más relacionada con emociones y corazonadas que con largos procesos de pensamiento lógico y argumentativo.

71 Keene, «Every boy and girl a scientist», 276-277.

72 Malcolm Gladwell, Inteligencia intuitiva (Madrid: Taurus, 2005).
} 
Como se ha mostrado, la dimensión formal renovadora y la no formal, dominada por los ejercicios empresariales innovadores, no permanecieron indiferentes una a la otra, sino que en las operaciones comerciales reflejadas en los catálogos de material educativo se reservaron secciones para el aprendizaje activo donde había alusiones a los artilugios de los fabricantes dedicados al juguete instructivo.

Hay sin embargo diferencias reconocibles entre estas dos dimensiones. Ya se ha señalado el sesgo de género explícito en la publicidad de la marca empresarial, una tendencia que no se reproduce en los planteamientos teóricos de la escuela activa, si bien en el reparto de las tareas de los trabajos manuales aún se establecían divisiones rígidas según sexos. Además, como se ha indicado, en la escuela activa se pretendían fomentar ideales de participación en la vida social, democráticos y progresivos. ${ }^{73}$ Sin embargo, los proyectos empresariales, en particular el aquí analizado, apelan a una sociedad tecnológica que asegure la prosperidad a una nación, propósito que proporcionaba una imagen convincente a las familias que adquirían los productos con la seguridad de que iban a ser provechosos para sus hijos.

\section{Nota sobre el autor}

Víctor Guijarro Mora es doctor en Filosofía y profesor de Historia de la Ciencia en la Universidad Rey Juan Carlos de Madrid desde 1999. Sus líneas de investigación principales son los estudios culturales de la tecnología y la cultura material de la enseñanza científica. Ha participado en seis proyectos financiados por el Plan Nacional de I+D. Los resultados de los proyectos más recientes se difundieron a través de la obra de LópezOcón Cabrera, Leoncio (ed.). Aulas Modernas. Nuevas perspectivas sobre las reformas de la enseñanza secundaria en la época de la JAE (1907-1939) (Madrid: Universidad Carlos III de Madrid, Editorial Dykinson, 2014), y de la obra -como autor- de Artefactos y acción educativa: La cultura de los objetos científicos en la educación secundaria en España (1845-1930) (Madrid: Universidad Carlos III/Dykinson, 2018). También ha editado junto con Leoncio López-Ocón y Mario Pedrazuela la obra Aulas abiertas Profesores viajeros y renovación de la enseñanza secundaria en los países ibéricos (1900-1936) (Madrid: Universidad Carlos III/Dykinson, 2019).

${ }^{73}$ Franco Cambi, Las pedagogías del siglo XX (Madrid: Editorial Popular, 2005), 29. 


\section{REFERENCIAS}

Adúriz Bravo, Agustín. «La propuesta didáctica del movimiento de la Escuela Nueva para la física: Argentina, 1921-1928». Revista Latinoamericana de Estudios Educativos (México) Vol. XXIX, no. 4 (1999): 151-160. Disponible en: https://www.redalyc.org/articulo.oa?id=270/27029405

Ballesteros Usano, Antonio. «Características de la enseñanza primaria en Francia, Bélgica y cantón suizo de Neuchatel», Junta para Ampliación de Estudios, Anales, XVIII, 1924.

Bordes, Juan. Historia de los juguetes de construcción. Madrid: Cátedra, 2012.

Borja i Solé, María de. El juego como actividad educativa. Instruir deleitando. Barcelona: Universitat de Barcelona, 1984.

Bowler, Peter. «Meccano Magazine: boys' toys and the popularization of science in early twentieth-century Britain». BJHS Themes 3 (2018): 129-146.

Brown, Keneeth D. The British Toy Business: A History since 1700. Londres: The Hambledon Press, 1996.

Cambi, Franco. Las pedagogías del siglo XX. Madrid: Editorial Popular, 2005.

Casa Editorial Dalmau, Carles, Pla, S.A. Catálogo de Material Escolar de la Casa Editorial Dalmau, Carles, Pla, Gerona-Madrid, curso 1934-1935.

Corredor, José. El juguete en España. Madrid: Espasa, 1999.

Cossío, Manuel B. El maestro, la escuela y el material de enseñanza y otros escritos, edición de Eugenio Otero Urtaza. Madrid: Biblioteca Nueva, 2007.

Dewey, John. Democracia y educación. Una introducción a la filosofía de la educación. Madrid: Ediciones Morata, 1998.

Dewey, John. Experiencia y educación, edición de Javier Sáenz Obregón. Madrid: Biblioteca Nueva, 2010.

Estalella, José. «La simplificación del material escolar de Física y Química», Enseñanza media 80-83 (1960): 635-660.

Ferrière, Adolphe. «École». En Sébastien Faure Encyclopédie anarchiste. París: La Librairie internationale, 1925-1934, tome 2, 622-623.

Frink, R. O. «El valor educativo de las ciencias y su papel en una enseñanza moderna», Acción naturista 141 (septiembre 1930): 273-280.

Giner de los Ríos, Francisco. Obras selectas, ed. de Isabel Pérez-Villanueva Tovar. Madrid: Austral, 2004.

Gladwell, Malcolm. Inteligencia intuitiva. Madrid: Taurus, 2005.

Gordon, Peter y Denis Lawton. Dictionary of British Education. Londres: Woburn Press, 2005.

Guijarro, Víctor y Leonor González. «La presencia de la tecnología en la utopía pedagógica: el Instituto de San Isidro y los Institutos-Escuela promovidos por la JAE». En El Instituto de San Isidro. Saber y patrimonio. Apuntes para 
una historia, editado por Leonor González y Vicente J. Fernández, 173-197. Madrid: CSIC, 2013.

Guijarro, Víctor. Artefactos y acción educativa. La cultura del objeto científico en la enseñanza secundaria en España (1845-1930). Madrid: Dykinson, 2018.

Jacobson, Lisa. «Manly Boys and Enterprising Dreamers: Business and the construction of the Boy Consumer, 1910-1930». Enterprise and Society 2, no. 2 (2001): 225-258.

Junta para Ampliación de Estudios (1925 a 1931), [Memorias correspondientes a los cursos 1922-3 a 1929-30], Madrid.

Junta para Ampliación de Estudios. Anales, XVIII, 1924.

Keene, Melanie. «Every boy and girl a scientist. Instruments for children in Interwar Britain». ISIS 98, no. 2 (2007): 266-289.

León Maroto, Andrés y Miguel A. Catalán. Exposición de la enseñanza cíclica de la Física y la Química. Madrid: JAE, 1931.

López Martínez, José Damián et al. «Patrimonio, cultura material e innovación docente: Propuestas y experiencias». Educació i Història: Revista d'Història de l'Educació 26 (2015): 89-120.

Lozano, Edmundo. «Pedagogía de las ciencias físico-químicas», BILE 36, 631 (1912): 289-293.

Maestro, Pilar. «Lorenzo Luzuriaga y la educación republicana». Pasajes: Revista de pensamiento contemporáneo 21-22 (2007): 19-42.

Marín Eced, Teresa. «Influencias europeas en la formación profesional de docentes españoles durante la II República Española». Revista de Educación 285 (1988): 93-110.

Material Escolar y Científico. Catálogo general A-38 de material de enseñanza. Barcelona [c.1930].

McReavy, Anthony. The Toy Maker. The Life and Times of Inventor Frank Hornby. Londres: Ebury Press, 2007.

Meccano. Instructions for $n .^{\circ} 1$ Outfit.

Otero Urtaza, Eugenio, Manuel Bartolomé Cossío: pensamiento pedagógico y acción educativa. Madrid: Centro de Publicaciones del Ministerio de Educación y Ciencia, CIDE, 1994.

Payá Rico, Andrés. «Aprender deleitando. El juego infantil en la pedagogía española del siglo XX». Bordón. Revista de Pedagogía 65, no. 1 (2013): 37-46.

Payá Rico, Andrés. «El juego popular y tradicional en la historia de la educación española contemporánea». Historia de la Educación 38 (2019): 39-57.

Payá Rico, Andrés. «El juego y el juguete en la historia de la escuela». En Escoles $i$ mestres: dos siglos de historia y memoria en Valencia, coordinado por Óscar Barberá y Alejandro Mayordomo Pérez, 137-152. Valencia: Universidad de Valencia, 2017. 
Redondo Castro, Cristina. «La segunda enseñanza pública en Extremadura, 1900-1936». PhD. diss., Universidad de Málaga, 2018.

Rodríguez Mata, Ángel. «El método activo aplicado en las escuelas de Francia y Bélgica», Junta para Ampliación de Estudios, Anales, XIX, 1924.

Tissandier, Gaston. Recreaciones científicas. Madrid: Cárlos Bailly Baillière, 1882.

Trilla Bernet, Jaume. La educación fuera de la escuela. Ámbitos no formales y educación social. Barcelona: Ariel, 1993.

Vallone, Lynne (2017). Big and Small: A Cultural History of Extraordinary Bodies. New Haven y Londres: Yale University Press, 2017.

Van Beek, Viola. «Experimental spaces outside the laboratory - Experiment kits and instruction manuals around 1900». The Virtual Laboratory, 2009, Disponible en http://vlp.mpiwg-berlin.mpg.de/references?id=art73). 